\title{
BORGES EN EL EJERCICIO DE LA CRÍTICA LITERARIA: A PROPÓSITO DE INQUISICIONES Y OTRAS INQUISICIONES (PRIMERA PARTE)
}

\author{
Alí Víquez Jiménez
}

\begin{abstract}
RESUMEN
El siguiente artículo es el primero de una serie de tres que se dedican a contrastar las diferencias que en el ejercicio de la crítica literaria se dieron fundamentalmente en dos libros de Jorge Luis Borges, Inquisiciones, de 1925, y Otras Inquisiciones, de 1965. En la medida en que las orientaciones teórico-literarias de Borges no se hacen explícitas en ninguno de los dos libros, el ejercicio consiste en deducir los presupuestos que subyacen en la práctica crítica de Borges. Este primer artículo examina concretamente las relaciones entre agnosticismo y crítica literaria y entre arte e historia que se proponen en Otras Inquisiciones, y las contrasta con la promoción del criollismo que se presenta en Inquisiciones.
\end{abstract}

Palabras clave: crítica literaria, Jorge Luis Borges, Inquisiciones, Otras Inquisiciones.

\begin{abstract}
This article is the first of a three-part publication which contrasts the differences in praxis of literary criticism reviewed essentially in two books by Jorge Luis Borges: Inquisiciones (1925) and Otras Inquisiciones (1965). Even though Borges' theoretical and literary orientation is not explicit in any of these two books, the present analysis seeks to infer the tendency that establishes his practice of criticism. The first article examines specifically the relationships both between "agnosticism" and literary criticism, and between art and history (as proposed in the book Otras Inquisiciones), thus contrasting these with the growth of "criollismo", recapitulated in the book Inquisiciones. Key words: literary criticism, Jorge Luis Borges, Inquisiciones, Otras Inquisiciones.
\end{abstract}

\footnotetext{
Alí Víquez Jiménez. Profesor de la Escuela de Filología, Lingüística y Literatura, Universidad de Costa Rica. San Pedro, San José, Costa Rica.

Correo electrónico: aviquez@yahoo.com

Recepción: 09-02-2005

Aceptación: 01-03-2005
} 


\section{Borges y la navaja}

El agnóstico se rehúsa a pretender que el entendimiento humano pueda penetrar en el absoluto. Frente al creyente, que afirma la existencia de Dios, y frente al ateo, que la niega, el agnóstico sostiene la incapacidad de un primate de pelo escaso para llegar a conclusiones al respecto. ¿Es este un acto de humildad? Acaso no lo sea tanto como de economía, una liberación que efectúa el pensamiento en relación con la carga sobrante e inútil. Así nos lo parece en el caso de uno de sus principales defensores y precursores, Guillermo de Occam, quien, navaja en mano, se apresuraba a excluir de sus reflexiones la consideración de aquellas entidades innecesarias por indemostrables, y cuyo afán último, atenuado por las circunstancias históricas de una Edad Media demasiado perseguidora de heterodoxias, probablemente era abandonar las cuestiones teológicas en favor de problemas científicos y lógicos. Este es el paso que dan otros grandes agnósticos, lejos ya de las torpes presiones eclesiásticas, como Auguste Comte, quien identificaba el estadio infantil de la humanidad con aquel en el que se imaginan una serie de causas míticas para explicar los fenómenos (Martínez Echeverri 1997: 84-5). Creía Comte necesario el superar este estadio para llegar a la madurez de un pensamiento aplicado, ahora sí, solo a lo que se puede resolver.

Por ello, no debería dejar de sorprendernos un proceder como el de Jorge Luis Borges, quien más bien determina que el agnosticismo autoriza a la imaginación para transitar por todos los caminos de la metafísica, puesto que, al fin y al cabo, ninguno de ellos es desechable por la vía de la razón o el entendimiento humanos. Si Occam esgrime una navaja, Borges en cierto sentido sirve un festín: el de la imaginación metafísica, que apertrechada en un agnosticismo radical, se siente libre para consumir toda clase de banquetes. La postura de este agnóstico argentino está clara: ya que de por sí no obtendremos nunca un conocimiento absoluto del universo, hemos de deleitarnos en las posibilidades que ofrece la imaginación. Los fines del pensamiento dejan de ser primordialmente epistemológicos u ontológicos, para convertirse, sobre todo, en fines estéticos. Como sostienen los sabios filósofos de Tlön en el famoso relato de 1941, el objetivo no es tanto procurarse el conocimiento como provocar el asombro, y a este se suele ligar el hecho estético, el fundador de la literatura, que solo existe cuando se produce la inefable emoción de la lectura en un lector concreto. Sin el encuentro del lector con el texto, por medio del cual se genera el hecho estético, un libro es solo una cosa más puesta en el anaquel; la filosofía en Tlön sirve para que ese encuentro ocurra de manera exitosa.

Veamos que Borges se negó a delimitar un concepto de hecho estético. La emoción en el arte siempre es misteriosa, el resultado de un proceso que no se conoce, la punta apenas del iceberg inmenso e imprevisible. En una conferencia de Siete Noches (1980: 105-21), insiste en la imposibilidad de reducir esta experiencia emocional a una definición que estaría, en el mejor de los casos, incompleta, y que, más probablemente, sería errónea. Si se decide por considerar algunas ideas al respecto de Bennedetto Croce, lo hace por creer que este crítico, a quien podríamos identificar como un espiritualista psicologizante de no demasiado prestigio en el mundo teórico actual, es el "menos nocivo", en la medida en que, justamente, casi no hace teoría; la elude entre términos seudo místicos a la hora de explicarse: la literatura como expresión sublime del alma, por ejemplo. Borges lo cita vagamente, y sigue su camino hacia la poesía (el tema de la conferencia) estableciendo que el hecho estético es el resultado del encuentro entre el lector y el libro, y la consecuente emoción o sensación, por lo general de asombro, que se produce entonces. Ahora bien, el ligamen entre el hecho estético y la sensación del asombro - esta última, originaria de las reflexiones filosóficas, de acuerdo 
con el propio Borges y muchos otros- no puede considerarse sino una de las posibles relaciones entre un estado emocional dado y el hecho estético, que es demasiado misterioso y no acepta una definición que lo determine como un enlace constante con alguna suerte de experiencia: el hecho estético se siente, es una vivencia incluso muy frecuente, pero no siempre es la misma. Recuérdese el caso de Herbert Quain, el personaje-escritor de un relato incluido en Ficciones (Borges 1991: 81-2), quien, por limitar su arte a una producción del asombro, se mira a sí mismo con desdén, y admite pertenecer no tanto al arte como a la historia del arte, disciplina de ínfima importancia: este es el precio que pagan los que se atienen a las definiciones rígidas.

Diríamos, pues, que es en el terreno de las teorías literarias (que no sin malicia llama "doctrinas") donde Borges pretende manifestarse como un agnóstico de afiladísima navaja: cuanto menos se teorice, mejor.

Consideremos en primer término que esta voraz navaja teórica está en manos de un autor tenido en diversos círculos como centro de referencia canónica. Premio Cervantes —el galardón más importante en el mundo literario hispánico-, eterno candidato al premio Nobel, que no recibió debido a sus veleidades políticas y flirteos ingenuos con la derecha, Borges es, junto a Neruda, uno de los dos latinoamericanos incluidos en el selectísimo grupo de los veintiséis autores indispensables de la literatura occidental, de acuerdo con el polémico libro de Harold Bloom, El canon occidental (1995: 11-50). No nos interesa aquí el participar de esa polémica, en la que sin duda Bloom, por la falta de elaboración de sus patrones valorativos, lleva las de perder a nivel de discusión teórica, pero las de ganar en cuanto a preferencias del gran público, que a juzgar por el éxito de su libro, lo sigue y lo celebra. Con Bloom, como con el mismo Borges, nos resulta importante mantener un oído atento a sus aciertos, aunque estos se den en medio de erratas teóricas, o al menos silencios en la disciplina. Es especialmente relevante que, según Bloom, Borges ocupa un sitio en el canon occidental por su enorme "poder de contaminación":

Si lees a Borges a menudo y con atención, te vuelves un tanto borgesiano, pues leerle es activar una conciencia de la literatura en la que él ha ido más lejos que ningún otro (1995: 481).

Resulta entonces que el agnóstico Borges provee a sus seguidores de una conciencia literaria en la que ha profundizado más que cualquiera, y esto -aparente y sorprendentemente-sin hacer teoría. Desembocamos así en nuestra segunda consideración en torno a la navaja teórica borgesiana, consideración ontológica ahora: ¿podemos creer en su existencia? ¿Es verdaderamente Borges un autor que se abstiene de hacer teoría? En otras palabras: ¿no deberíamos aplicarle a la supuesta navaja teórica borgesiana la propia navaja que se deshace de los entes inexistentes? Veamos que entre otras razones por las que justifica su divorcio de la teoría, Borges arguye:

Soy casi incapaz de pensamiento abstracto, ustedes habrán notado que estoy continuamente apoyándome en citas y recuerdos. Mejor que hablar abstractamente de la poesía, que es una forma del tedio o de la haraganería, podríamos tomar dos textos en castellano y examinarlos (1986: 108).

A la vista de la obra de Borges: ¿resulta creíble su incapacidad para el pensamiento abstracto? Un lector lo suficientemente familiarizado con el sentido del humor borgesiano sabe que a menudo este se presentaba bajo la forma de declaraciones contradictorias entre sí o abiertamente contrarias a sus verdaderas opiniones. (También Pierre Menard escribía artículos con "el reverso" de sus ideas. Véase Borges 1991: 50.) Además, resultaba notoria la tendencia 
del "anciano terrible" por empecinarse en ir contra lo que él creía que esperaban declarase. Ya no se trata solo de las razones que arguye Bloom sobre por qué Borges es un autor digno de representar el canon literario occidental, sino de una evidencia a los ojos hasta del lector borgesiano menos avisado: estar frente a un autor que reflexiona sobre la literatura, que la observa de manera crítica, la sopesa, la valora y que aspira a transmitir ideas al respecto. No es otra cosa la teoría literaria, si bien su rigurosidad y validez pueden variar mucho al tomar en cuenta cómo se realicen estas operaciones.

Admitamos que el hecho estético no se pueda reducir a una descripción exhaustiva; esto lo compartimos con Borges, quien lo considera "...tan evidente, tan inmediato, tan indefinible como el amor, el sabor de la fruta, el agua” (1980: 110). No se sigue de aquí el que la teoría tampoco pueda recorrer otros caminos. Sostener lo inválido de la elaboración abstracta en torno a la literatura porque no se puede dar cuenta de lo que la misma literatura sabe que es inefable (ese hecho estético misterioso que ocurre en el lector cuando se encuentra con el texto) es generalizar apresuradamente: un espacio en el que no se logra teorizar no implica la inexistencia de los demás espacios. Y, en el contexto borgesiano, siempre lleno de reflexiones abstractas en relación con la literatura, ello resulta especialmente obvio.

Borges ejerció la crítica literaria. Numerosos comentarios dedicados a las obras ajenas, y realizados en el transcurso de muchos años, quedan como evidencia. Pero acaso la evidencia más poderosa de que Borges ejerció la crítica se halle en esa idea fundamental para su propia producción, y que Harold Bloom señala con acierto (es lo que antes llamó "conciencia de la literatura"):

\footnotetext{
Esta conciencia, a la vez visionaria e irónica, es difícil de describir, pues acaba con esa antítesis discursiva entre lo individual y lo común. Tiene que ver con el hecho de reconocer que, en mayor o menor medida, toda la literatura es plagio... (1995: 481).
}

La literatura de Borges -y este lo supo bien - no le pertenece a Borges: es del otro, de la tradición, del lenguaje. Borges no cree en la originalidad, en la posesión personal de los discursos: quien habla está hablando por la boca de los demás. Por eso hacer literatura es irremediablemente hacer crítica de la literatura, aunque no sea más que por el gesto de valoración que se realiza cuando se decide escribir sobre y desde determinado texto.

Por lo demás, las palabras de Borges citadas, en las que pretende saltarse cualquier teoría (esa forma del tedio o la haraganería), para hacer la crítica directamente, se pueden cuestionar por el lado de una discusión que ya es añeja, pues proviene de 1966, año de la publicación de Crítica y verdad. Cuando la crítica no explica sus bases teóricas, simplemente las impone sin discutirlas. No se puede eludir el hacer crítica desde cierto lugar, y en este lugar están implícitos los conceptos sobre la literatura, su función, validez y posibilidades, sobre la función de la crítica, sobre la relación de esta con otros discursos. El examen de la crítica que calla sus bases de trabajo (la "metacrítica") tiene una importancia señalada, pues nos enfrenta con una serie de presupuestos, una serie de "no dichos", espacios que significan más todavía en tanto callan.

Así llegamos a lo que nos ocupará en las páginas que siguen. Borges como crítico literario pretendió aplicar la navaja de Occam a la teoría literaria. Pero no es tan fácil ocultar el rastro de los presupuestos teóricos: estos siempre quedan; borrarlos enteramente solo puede hacerse borrando por completo el discurso crítico. Nos interesa, entonces, rastrear esos presupuestos. El ejercicio será de "metacrítica". No pretendemos situarnos en una posición superior 
a Borges, en el sentido de estar hablando desde un espacio de mayor lucidez. Gran ingenuidad la cometida por algunos estudiosos de la literatura, que parecen despreciar el discurso que ha fundado su saber, y hablan de la literatura en términos de quien conoce sus secretos mejor que nadie. Más bien queremos seguir, en el ámbito de la teoría, el saber borgesiano que el propio autor no llegó a precisar. (No es lo mismo, lo ha dicho Lacan, el saber que el conocimiento.) Borges se interesó en recorrer más otros senderos entre los numerosos que se ofrecieron a su mente voraz; esta investigación se justifica precisamente porque aquí nos dejó caminos poco iluminados por los que vale la pena tratar de lanzar luz. No está de más recordar que la luz de la biblioteca de Babel es descrita a la vez como incesante e insuficiente (Borges 1991: 90).

Ya hemos visto que toda la obra borgesiana podría leerse como ejercicio crítico. Sin embargo, hemos decidido centrar nuestra atención en dos libros precisos: Inquisiciones y Otras Inquisiciones. Pasamos a explicar las razones para ello.

En primer lugar, se encuentra la evidencia de que en estos libros la crítica literaria constituye el asunto central. Esta es una aseveración cuantitativa: alrededor del $80 \%$ de los libros tiene por objetivo el hacer crítica explícita de algún texto literario, si bien a veces poniendo el énfasis en el aspecto biográfico del autor, pero esta ha sido siempre una de las formas de la crítica literaria. Así, podemos esperar que los libros borgesianos predominantemente críticos nos den una orientación más completa sobre las ideas de Borges relacionadas con esta práctica de escritura, sin que esto sea impedimento para eventualmente contrastar los resultados de esta investigación con la información que pueda obtenerse en otras fuentes de la extensa bibliografía de Jorge Luis Borges. En particular, habrá que prestar atención a un libro que puede considerarse una continuación, en algunos sentidos, de Inquisiciones, y que compartió su suerte editorial con él: El tamaño de mi esperanza.

En segundo lugar, y a propósito todavía de navajas, vale la pena recordar la historia de estos textos; en particular, del más antiguo, Inquisiciones. Este se publicó por primera vez en 1925, con un tiraje limitado y una circulación pobre. Borges tiene entonces apenas 26 años, y no es ni de lejos el reconocidísimo autor que llegó a ser más tarde. Solamente ha publicado un primer libro de poemas, Fervor de Buenos Aires (1923), aunque ya ha sido colaborador entusiasta de algunas revistas, entre otras, aquellas en cuya fundación él participó: Prisma y Proa. En ese mismo año de 1925, publicará su segundo libro de lírica: Luna de enfrente.

Cuando, mucho después, Borges se convierta en un escritor de prestigio, le sobrarán proposiciones editoriales para reeditar Inquisiciones, proposiciones que él rechazará con vehemencia. Incluso, Borges solía molestarse cuando algún crítico interesado en su obra lograba rastrear algún remoto ejemplar de este libro y le prestaba atención. Así, el texto se convierte en un espacio prohibido por el autor, quien decide aplicar la navaja a todas estas primeras Inquisiciones. Lo mismo pasó con El tamaño de mi esperanza (1926) y El idioma de los argentinos (1928). Ninguno de los tres libros conoció segunda edición mientras Borges estuvo con vida: la navaja actúa con una voracidad impresionante, pese al ruego de gran cantidad de estudiosos borgesianos, que recurren a fotocopias clandestinas para completar sus bibliografías. (Por otra parte, en relación con su identificación juvenil con el movimiento ultraísta, que influyó en parte de su producción lírica inicial, Borges no ha podido ser más elocuente, al referirse luego a ese periodo con el apelativo de "equivocación ultraísta”).

Sin embargo, la navaja no dejó de actuar, asimismo, de manera un tanto equívoca. Aplicada con severidad sobre Inquisiciones, dejó que este título se escapara y continuara creciendo. Nos referimos al hecho de que Borges titula con el nombre de Otras inquisiciones un 
libro posterior, cuya primera edición es de 1952, pero que el autor sigue enriqueciendo hasta 1965. El texto apunta a ser, de acuerdo con su título, una continuación del libro anterior, el libro prohibido. ¿O acaso deberíamos leer en un sentido diferente la palabra "otras"? ¿Quiere decir no las inquisiciones siguientes, su continuación, sino las diametralmente distintas, su divergencia? Lo cierto es que el diccionario nos permite tomar ambos caminos. Responder a estas preguntas es también el objetivo de las siguientes páginas.

Ahora bien: ¿cómo ha llegado hasta nuestras manos el libro prohibido que nos interesa? La contestación puede parecer meramente anecdótica: a la muerte de Borges, en 1986, su viuda, María Kodama, se convierte en su heredera universal y, por lo tanto, queda a cargo de tomar las decisiones que antes tomaba Borges sobre qué publicaciones autorizar. En 1993 o poco después salieron a la luz Inquisiciones, El tamaño de mi esperanza y El idioma de los argentinos. Según Kodama, solo se trató de regularizar la reproducción y la distribución de unos libros que de por sí ya andaban en forma de fotocopias y ediciones piratas en las manos de los estudiosos y los aficionados a Borges. Es evidente que sobre este tipo de publicaciones informales no se cobran los correspondientes derechos de autor, pero esto último no forma parte de las declaraciones de la viuda de Borges. De todos es sabido que el anciano ciego vivía sumamente distraído del precio de mercado de sus libros, o de los libros en general: Borges jamás sospechó que la literatura se pudiera considerar una mercancía. Un muerto, sin embargo, no puede protestar.

\section{En el jardín de lecturas que se bifurcan}

La imagen lineal que nuestra cultura suele privilegiar acerca del tiempo (un espacio asimilable a una línea en el que se ordenan los instantes pasados, el instante presente y los instantes futuros, en una sucesión inamovible) ha sido cuestionada desde la óptica borgesiana en diversos textos. Recordemos uno: "El jardín de senderos que se bifurcan" (1991: 101-16). El tiempo se asimila a un laberinto que, como el jardín de Stephen Albert quisiera de un modo tenue sugerir, puede recorrerse de maneras muy diversas. Su lógica no se basa en la linealidad, sino en la bifurcación: infinitas posibilidades se ofrecen a cada paso; el tiempo no es una línea, es una infinitud de ellas, un jardín de senderos interminables. Esta idea del tiempo ha sido generada en la ficción por Ts'ui Pên, que también ha escrito un libro para ilustrar el carácter laberíntico del tiempo. Se trata de una novela caótica, en palabras del sinólogo Stephen Albert, pues pretende construir no una trama, sino una multitud de ellas: las que cabrían en los numerosos senderos del tiempo. Ahora bien: entendamos que Borges no está solo sugiriendo una forma de ver un libro preciso, sino una forma de entender toda la literatura. El texto es un laberinto que se recorre de maneras diversas; una lectura nunca es igual a otra, ni siquiera cuando la realiza el mismo lector, pues en la segunda ocasión el lector está tomando otra bifurcación en el tiempo. El hombre de ayer no es el hombre de hoy; tampoco el lector de ayer es el lector de hoy. Se recorre un camino una vez; luego es imposible repetirlo. Yu Tsun reflexiona, un tanto tristemente, que “...todas las cosas le suceden a uno precisamente, precisamente ahora" (1991: 102). Y es imposible volver sobre el ahora cuando este ya no existe sino como recuerdo. Solo se deja de recorrer nuevos caminos con la salida del laberinto, que es lo que Yu Tsun hace por Stephen Albert: lo asesina. La muerte es la única puerta. Continuar viviendo es prolongar la lectura; de la caótica novela de Ts'ui Pên también se sale solo por la vía de la muerte. Más aún: la literatura y el lenguaje, asimismo, solo se abandonan por la muerte. 
Siguiendo la idea de lectura que sugiere esta historia, habremos de leer a Borges de una manera borgesiana: nos enfrentaremos con su texto crítico recorriéndolo sin pretender en él un orden lineal o una cronología inamovible. Ello nos permitirá transitar por los textos en diversas direcciones, a sabiendas de que nunca se vuelve sobre el camino recorrido. En este primer artículo, en concreto, transitaremos de lo más reciente a lo más antiguo, de Otras inquisiciones a Inquisiciones, y sin seguir la linealidad interna de ambos libros. Otros senderos se dejarán para más adelante.

\section{Los rigores del escepticismo}

En el epílogo ya de Otras inquisiciones, Borges realiza un examen de conjunto del volumen y determina dos tendencias. La primera tiene que ver con "un escepticismo esencial". Borges valora una idea religiosa o filosófica por "...su valor estético y aun por lo que encierran (esas ideas) de singular y de maravilloso" (1983: 247). No hay espacio para la discusión sobre lo que hay de verdadero en esos planteamientos: es el rigor del escepticismo que de por sí descree de cualquier posibilidad de conocer la verdad de una forma segura. Es conocida la sentencia borgesiana que equipara la filosofía con una rama más de la literatura fantástica. ¿Significa esto que el escepticismo de Borges se desentiende alegremente de cualquier preocupación por la verdad? Más bien lo contrario: todas las ideas le resultan importantes, en la medida en que en cualquiera de estas especulaciones metafísicas podría encerrarse una verdad. Borges juzga improbable que sepamos cuál camino nos conduce a la verdad, pero también cree improbable que ninguno lo haga, al menos parcialmente (véase Herrera 1987). Ya vamos entendiendo por qué su escepticismo lo conduce por tantas avenidas del sentido: es un lector que no sabe abstenerse de sospechar la verdad en todas partes, sin determinarla con certeza en ningún sitio.

Así funciona también el crítico. Cada visita que Borges realiza por algún texto es una forma de manifestar su sospecha sobre la pretensión de verdad que encierra ese texto. Hablamos de sospecha en el sentido más amplio: el que significa duda, irresolución; el que concede la posibilidad del acierto pero no se resuelve a afirmarlo ni a negarlo. Como en la biblioteca de Babel (1991: 89-100), donde ningún bibliotecario puede estar seguro de no tener muy cerca el libro fundamental, que lo resuelve todo, el crítico borgesiano examina los textos con la indecisión que le produce el escepticismo. Ese es su rigor. Como en "Los teólogos" (1989: 37-48), cuyos protagonistas transitan por muy diversas especulaciones metafísicas para descubrir al final que Dios no tiene el menor interés en lo que ellos han llegado a creer, puede que la verdad se halle tan lejana de nuestro pensamiento personal que todos nuestros esfuerzos hayan sido vanos. Ese es el riesgo.

\section{Las limitaciones de la metáfora y la fabulación}

La segunda tendencia que comenta Borges en el epílogo de Otras inquisiciones es la siguiente: “...a presuponer (y a verificar) que el número de fábulas o de metáforas de que es capaz la imaginación de los hombres es limitado, pero que esas convenciones pueden ser todo para todos, como el Apóstol" (1983: 247).

Es una tendencia que introduce una limitante a los sentidos posibles, en la medida en que las lecturas se han de orientar sobre ciertos espacios de la imaginación que se repiten. Es como si Borges determinara que existe un contrapeso para las infinitas posibilidades de los 
textos literarios comentadas en el apartado anterior. Ahora bien, esto debería matizarse del siguiente modo: Borges no ha declarado que las interpretaciones de las metáforas o fábulas sean limitadas. Metáforas y fábulas no son infinitas, pero sus lecturas sí podrían serlo.

De todos modos, estamos ante otro panorama: el crítico podría -en la teoría, al menos - moverse de muchas maneras, acaso de infinitas maneras, en la biblioteca, que otros llaman el universo (1991: 89). Pero lo que hace es moverse por unos cuantos espacios metafóricos o fabulescos. Es lo que Borges afirma en Otras inquisiciones: no debe escapársenos que él mismo acepta esto como un presupuesto de su actividad como lector (y también como crítico): "presuponer", dice, es lo que hace, y luego, claro (el planteamiento es circular), "verificar" lo presupuesto.

Todos los textos pueden recorrerse; en todas partes se puede esconder la verdad y esto lo sabe el rigor del escéptico; el bibliotecario tiene un universo infinito de signos ante sí, que muchas veces mira con estupor, cuando no con horror, pues se le evidencian sus pequeñeces, su ínfima probabilidad de acierto, que en la "Biblioteca de Babel" se declara "computable en cero". Pero una limitante se impone: de esos textos innumerables -muchos de ellos inexpugnables para el ser humano- solo se recorren -o, si se quiere, solo se comprenden - aquellos que son variaciones de unas cuantas propuestas de la imaginación.

Entendamos que esta no es solo una premisa para aplicarse en la labor crítica: es, de acuerdo con Borges, una evidencia de la condición humana: el hombre está limitado a solo ciertas "fábulas" o "metáforas". Examinemos cuáles son las consecuencias de esta afirmación, en el texto de Otras inquisiciones.

\section{Todo para todos}

Lo que está dado por el arte es lo mismo que está dado por la historia. Es una aseveración que Borges ofrece al principio de "La esfera de Pascal", el segundo de los ensayos de Otras inquisiciones: "Quizá la historia universal es la historia de unas cuantas metáforas" (1983: 13).

Las implicaciones son severas. Se afirma la asimilación de la historia humana, de toda la historia humana (la llama universal) con el arte, y en la concepción limitante de arte que ya hemos venido explicando se da en el Borges crítico: el que lee proyectando los textos sobre unos cuantos espacios de la imaginación, a los que llama fábulas o metáforas. Volveremos sobre las implicaciones de lo que ahora llamamos "proyección"; por el momento, vamos a señalar la evidencia de que Borges ha tomado el camino del idealismo más extremo al elaborar una noción de historia. No en balde el creador del idealismo subjetivo, George Berkeley, es uno de sus filósofos favoritos, comentado con ironía en ocasiones, pero no sin profunda admiración. Muchas veces parece que Borges desearía que Berkeley, el ingenioso negador de la sustancia material, tuviera razón, pero lo golpea la convicción de que no es así: cuando en el ensayo final de Otras inquisiciones, y basado en los argumentos del idealismo subjetivo, llega a refutar la existencia del tiempo, vuelve sobre sus pasos para relativizar la validez de sus razonamientos:

Negar la sucesión temporal, negar el yo, negar el universo cósmico, son desesperaciones aparentes y consuelos secretos. Nuestro destino (a diferencia del infierno de Swedenborg y del infierno de la mitología tibetana) no es espantoso por irreal; es espantoso porque es irreversible y de hierro(...) El mundo, desgraciadamente, es real; yo, desgraciadamente, soy Borges (1983: 240). 
Pero el descreimiento final en relación con Berkeley (a menudo Borges cita a Hume, quien dijo que los argumentos de Berkeley al negar la existencia de la sustancia material no admiten la menor réplica ni producen la menor convicción) se da, y esto es lo notable, en el plano de lo personal (cada quien es quien es y su destino es irrefutable) y de lo cósmico y ontológico (el mundo es real; el ser tiene sustancia), pero no en el plano de lo histórico. Allí sigue siendo válida la propuesta según la cual la historia se organiza como un espacio de fabulación y metaforización, en el cual el misterioso hecho estético tiene lugar como principio rector.

Esa dimensión exagerada cobra su noción de hecho estético. No se relaciona únicamente con la actividad artística, se relaciona con toda la actividad simbólica humana. En "La muralla y los libros", Borges expone la inquietud que le causó enterarse de que el Emperador Shih Huang Ti ordenó la edificación de la muralla china y también la quema de todos los libros anteriores a su reinado. Aunque concede que "...históricamente, no hay misterio en las dos medidas" (1983: 9), esta es solo una concesión inicial, que se apresura a negar en el mismo párrafo: “...los hechos que he referido son algo más que una exageración o una hipérbole de disposiciones triviales". Observemos que la idea de que tales hechos tuvieran su origen en circunstancias concretas y políticas (“...erigió la muralla, porque las murallas eran defensas; quemó los libros, porque la oposición los invocaba para alabar a los antiguos emperadores" (1983: 9)) le parece insuficiente. Es más, le parece una trivialidad, pues en la medida en que tal explicación se atiene a hechos políticos, que en la opinión de Borges carecen de valor estético, se la puede desechar.

Quizá lo más parecido a una definición del hecho estético que podemos encontrar en la obra de Borges está justamente hacia el final de "La muralla y los libros", y de modo curioso no se articula con una discusión sobre arte sino con una especulación sobre la historia. O, más bien, habría que decir que es una reflexión sobre arte que viene a ofrecerse como explicación de acontecimientos históricos. Pero esto es, con toda probabilidad, una exageración de nuestra parte, puesto que Borges no acepta que se pueda "concluir", en el sentido de dar explicaciones finales: precisamente, la historia se parece al arte porque la culminan los hechos estéticos, y estos (he aquí lo que podría parecerse a una definición) se caracterizan por ser “...la inminencia de una revelación, que no se produce...” (1983: 12). Así, la historia, como el arte, calla su sentido último; no nos entrega una verdad, solo produce un gesto que la anuncia, y jamás la dice.

Otras inquisiciones viene a ser, así, un tránsito por unas cuantas metáforas o fabulaciones fundamentales, ya no solo para el arte, sino para la actividad simbólica general del ser humano. Borges pretende dar cuenta no solo de lo literario, sino de lo humano en general. Calla, eso sí, el sentido que puedan tener esas metáforas o fabulaciones; el sentido no es uno ni está limitado: es un jardín de senderos infinitos. (Habría que agregar que se da cuenta de lo divino también. Con "La esfera de Pascal" se introduce lo que Borges juzga como la metáfora dominante de la concepción humana de la divinidad: la forma de la esfera. No se trata de la divinidad tal como es, si es que es, sino de la posibilidad humana para imaginarla. El recorrido a través de diversas versiones de la esfera no pretende ser exhaustivo, como si se quisiera demostrar una difusión generalizada en distintos espacios y tiempos de la misma metáfora; pretende ser exacto, pues se aproxima a la mejor intuición posible de la divinidad, de acuerdo con las posibilidades humanas, según Borges).

Con esto llegamos a uno de los presupuestos fundamentales en el ejercicio de la crítica literaria borgesiana. Esto es, que su aproximación a los textos está siempre motivada por la concordancia entre una posibilidad de lectura del texto y una propuesta filosófica que el propio 
Borges suscribiría. En este sentido, la lectura de los textos que efectúa Borges es una lectura interesada y proyectiva: pretende ver en ellos las ideas propias que más le interesan. Esto es algo que no se ha declarado en el epílogo de Otras inquisiciones que hemos venido comentando: esos espacios de la imaginación que pueden ser "todo para todos" son, en primer lugar, "todo para Borges". El maestro, sin embargo, ha preferido callar su propia presencia y se cubre con un manto tan anónimo como exagerado: el de la totalidad de los seres humanos.

Así, la función de la crítica borgesiana de Otras inquisiciones consiste, en primer lugar, en efectuar una demostración de que su propio pensamiento filosófico se encuentra ya en los autores comentados. El crítico se lee en los textos; veamos que esta es una propuesta concordante con la tesis de Bloom sobre Borges y su idea de que en literatura todo es un plagio.

También en esta línea, vale la pena traer a colación otro de esos espacios de la imaginación que Borges juzga recurrentes en el pensamiento: el hecho de que todos los libros son escritos por un solo poeta, y resultan de una suerte de creación colectiva universal, una obra que proviene de la inspiración de un solo espíritu. Colectiva, hemos dicho, pero también, en buena medida, selectiva: todo el mundo participa de su elaboración, pero algunos lo hacen más que otros. Cuánto se colabore en esta titánica obra no es el resultado de una voluntad, sino de una capacidad para decir alguna de esas metáforas o fabulaciones que Borges considera esenciales.

Borges comenta la idea a propósito de Valéry (que escribe "Espíritu” con mayúscula), de Concord y de Shelley, y la aplica a Coleridge en dos ensayos sucesivos de Otras inquisiciones ("La flor de Coleridge" y "El sueño de Coleridge"), y también a Edward Fitzgerald; en ambos casos, el enigma de cómo se convierte alguien en un creador de tales espacios de la imaginación esenciales no se resuelve. Luego la reflexión va más allá, pues en "Magias parciales del Quijote", se establece que esta creación colectiva no solo es un producto llamado arte o lenguaje o libro (Borges prefiere este último término, pero oscila entre ellos), sino que abarca también al productor, al ser humano, que se hace en el lenguaje. La idea se atribuye a Carlyle originalmente, pero Borges la suscribe y hasta cree verla sugerida en las obras de Shakespeare, Cervantes y en Las mil noches y una noches: "...la historia universal es un infinito libro sagrado que todos los hombres escriben y leen y tratan de entender, y en el que también los escriben" (1983: 69).

Resulta interesante preguntarse qué es lo que da al libro infinito su carácter sagrado, si su origen divino o su carácter venerable, pero aquí Borges calla. El agnóstico se impone de nuevo. No obstante, vale la pena comentar un corolario de esta idea relacionado con la teoría literaria borgesiana: es esta creación colectiva misteriosa de la humanidad la que permite que un escritor sea el creador de sus espacios de contacto intertextual, como lo declara Borges en "Kafka y sus precursores". En este ensayo se encuentra el planteamiento singular de que, tras un examen cronológico de "...su voz, sus hábitos en textos de diversas literaturas y de diversas épocas" (1983: 137), se concluye que es Kafka quien ha producido o proyectado su influencia sobre los escritores previos. Kafka hace que sus precursores se lean de una manera kafkiana, antes inédita.

Hay, por otra parte, un claro juicio de valor relacionado con los escritores capaces de crear a sus precursores. A propósito de Hawthorne, se dice que "...un gran escritor crea a sus precursores. Los crea y de algún modo los justifica. Así, ¿qué sería de Marlowe sin Shakespeare?" (1983: 84). Que no se nos pase por alto: solo un gran escritor crea a sus precursores. Quien es verdaderamente grande (en primer lugar, Shakespeare, el centro del canon 
occidental, el "inventor de lo humano", según repite casi con beatería Harold Bloom) es quien modifica la forma como se leen sus precursores. Solo un gran escritor, entonces, será capaz de tomar el lugar de ese Espíritu con mayúscula de Valéry, que lo escribe todo. Borges coincide con Bloom en la valoración central de Shakespeare. Aunque con un dejo de incierta ironía, Borges cita a Coleridge, “...para quien Shakespeare ya no es un hombre sino una variación literaria del infinito Dios de Spinoza” (1983: 185). Shakespeare es lo más cercano que se pueda concebir como encarnación de ese Espíritu. Borges, en "De alguien a nadie", arguye que es falaz el razonamiento que termina borrando la identidad personal de Shakespeare, pero no el tenerlo como ejemplo preclaro de la encarnación, siquiera momentánea, de ese Espíritu.

Así se nos va completando un panorama global. Borges elabora una idea de literatura como construcción delimitada sobre ciertos espacios imaginativos que se repiten en el curso de la historia de la humanidad. No es este un proceso casual, sino un resultado del condicionamiento esencial de los seres humanos; estos espacios imaginativos exceden por ello el ámbito del arte y constituyen la historia universal. Sí es un proceso misterioso, pues por su medio se da el hecho estético, frecuente y fácil de identificar, pero imposible de definir. Cuando Borges sugiere que hay una suerte de Espíritu de la escritura, se distancia con la prudencia del agnóstico de la identificación mística del escritor con lo trascendente, en que incurren Valéry u otros, pero no se distancia de la concepción de literatura como una creación que repite espacios de la imaginación de una forma misteriosa, como en un sueño: "Schopenhauer ha escrito que la historia es un interminable y perplejo sueño de las generaciones humanas; en el sueño hay formas que se repiten, quizá no hay otra cosa que formas; una de ellas es el proceso que denuncia esta página” (1983: 186). El enunciado puede parecer dubitativo, pero no lo es en la medida en que constituye una de las bases teóricas desde las que se escribe Otras inquisiciones.

Ahora bien, el panorama global se completa con la proyección del pensamiento borgesiano sobre los autores estudiados, por la vía de la identificación y la apropiación de esos espacios imaginativos. Así, el crítico Borges practica lo que predica para los grandes escritores: está haciendo a sus precursores. Cuando lee, se lee; de este modo, se convierte en uno de los grandes.

No era solo su opinión. Por los cincuenta, y mucho más en épocas posteriores, Borges fue muy valorado, como ya hemos visto. Ahora bien: todavía no tanto como cuando se le contaba, en los setenta y ochenta, entre los clásicos de la literatura. Digámoslo con una licencia cronológica: Bloom aún no lo estaba incluyendo en su selecto grupo.

Por otra parte, ¿qué hay del joven desconocido de las Inquisiciones? Volvamos ahora nuestros ojos sobre este texto.

\section{Transiciones en el jardín}

En el apartado anterior, mencionamos que Borges considera que ciertas metáforas son esenciales. Esto implica que hay otras que no lo son. Así, se afirma que “...es quizá un error suponer que puedan inventarse metáforas. Las verdaderas, las que formulan íntimas conexiones entre una imagen y otra, han existido siempre; las que aún podemos inventar son las falsas, las que no vale la pena inventar" (1983: 71). Esta idea del Borges maduro resulta contradictoria con un postulado fundamental del movimiento ultraísta, que buscaba la novedad de la metáfora casi por encima de todo. El descubrimiento no es nuestro: ya hemos dicho que Borges acusó al ultraísmo de no ser sino una equivocación. 
No obstante, sería un error ubicar la escritura de Inquisiciones dentro del periodo ultraísta. Diversos textos incluidos allí señalan ya un distanciamiento al respecto por parte del joven Borges. Al presentar a González Lanuza, uno de sus compañeros o ex compañeros del movimiento ultraísta bonaerense, Borges no escamotea los calificativos para valorarlo positivamente, pero asimismo incluye la reflexión de que el movimiento ultraísta, que se pretendió "...el anhelo de recabar un arte absoluto que no dependiese del prestigio infiel de las voces y que durase en la perennidad del idioma como una certidumbre de hermosura..." (1993: 105), terminó por convertirse en uno más de esos movimientos artísticos históricos: “...he comprobado que, sin quererlo, hemos incurrido en otra retórica, tan vinculada como las antiguas al prestigio verbal” (1993: 106). Borges valora que el ultraísmo fuese una superación del modernismo de Darío (lo que él llama con desdén “rubenismo"), pues juzga que este se producía desde una retórica sumamente artificiosa, pero admite que en el ultraísmo no se generó un arte sin retórica, como había sido el (ahora lo sabe) ingenuo propósito: atrapar el absoluto de la expresión.

Este Borges de Inquisiciones no cree posible, pues, la ambición ultraísta de "hacer lírica nueva" (1993: 84). Entiende que la literatura no puede escribirse con recurso a la novedad absoluta: juzga ya un tanto adolescente tal propósito. En Inquisiciones, vemos a un Borges que valora ahora el equilibrio entre el afán de innovación y el inevitable tránsito por los textos previos. Así, dice sobre Thomas Browne, a manera de elogio: "Fue novador, pero no a semejanza de los que siguen el asombro y el sacar de quicio al leyente; fue clásico, pero sin mimetismo apasionado ni rigideces de ritual" (1993: 36). Este Borges, entonces, no se dedica a buscar absolutos, ni niega la validez de participar en la circunstancia humana, en el contexto histórico (y no se trata aquí de una historia como espacio para la imaginación, como se propondrá luego, según hemos visto, en Otras inquisiciones): “...la mayor grandeza de un hombre estriba en responder con su tiempo y en ocuparse con los afanes y lizas que son populares en él" (1993: 40).

La pregunta que nos surge es: abandonado el ultraísmo, que pretendía la innovación absoluta, ¿adónde va este Borges? Queremos responder, siguiendo lo que ha sido la orientación de este artículo inicial sobre el Borges crítico, en términos globales, por el momento. El plan que atraviesa el texto de Inquisiciones se puede leer así: en primer lugar, por medio del ejercicio crítico a propósito de diversos textos, Borges estudia el funcionamiento de la metáfora y se distancia del ultraísmo: "En mi opinión, no es dable urdir metáforas de una plenaria novedad. En todo el múltiple decurso que han seguido las letras castellanas no creo que pasen de una treintena los procedimientos empleados para alcanzar figuras novedosas" (1993: 130). Antecede a esta afirmación un ensayo llamado "Examen de metáforas", que quiere demostrar que todas las metáforas que permite el lenguaje se desprenden de unos pocos arquetipos inamovibles (1993: 71-81). En segundo lugar, Borges emprende la valoración, en modelos extranjeros como Cansinos Asséns, Gómez de la Serna o el mismo James Joyce (1993: 20-4), del interés por lo nacional, y lo recomienda: "Creo que nuestros poetas no deben acallar la esencia de anhelar de su alma y la dolorida y gustosísima tierra criolla donde discurren sus días. Creo que deberían nuestros versos tener sabor de patria, como guitarra que sabe a soledades y a campo y a poniente detrás de un trebolar" (1993: 20-1). Ha vuelto sus ojos al criollismo. Este camino se terminará de hacer patente en El tamaño de mi esperanza y El idioma de los argentinos.

Un examen del resto de Inquisiciones nos lo confirma. Se declara allí que la elección de un autor para someterlo a crítica es de por sí un juicio de valor positivo: 
Enderecemos el silencio a los playos escritorzuelos malévolos, un empellón agresivo a las nulidades con aureola y sitial, romos adjetivos laudatorios a los escritorzuelos simpáticos y un examen filoso y desbastado a las obras que palpitantemente viven (1993: 129).

Los textos críticos sobre Ascasubi, Ipuche y Silva Valdés son, dado el caso, significativos. Hay pasajes enteros que solo persiguen el valorar, y están cargados de una emotividad que se extiende a todo "el arte gauchesco": "La órbita del arte gauchesco ha sido siempre ribereña del Plata y el río innominado es como un armonioso corazón en la interioridad de su cuerpo y sus estrofas clásicas, que nada saben del chañar y del mistol, son decidoras del ombú y la flechilla" (1993: 63). Que no se nos pase algo importante en esta cita: hay una pretensión de atribuir categoría de "clásico" a este arte gauchesco. El joven Borges, que está reorientando su camino del ultraísmo hacia el criollismo, se prepara ya para convertirse en clásico.

La preparación es, sin embargo, de momento, un tanto ambigua. Todo el libro de Inquisiciones está marcado por un ejercicio de la crítica emocional y valorativo, en el que el joven Borges declara sus nuevos amores al tiempo que se distancia de los anteriores. Al hablar de los clásicos, oscila entre conceder este status a sus autores de arte gauchesco y cuestionar el criterio de valoración que hay implícito en la categoría de "clásico"; finalmente, deja el cuestionamiento. El Borges joven visualiza a la literatura como un espacio de competitividad en el que pocos llegan a los primeros sitios. Se distingue del Borges de Otras inquisiciones en su concepción de historia, que no profundiza, pero que no se percibe como cargada por completo del idealismo del Borges posterior. Digamos, sí, que en su estudio de las formas arquetípicas que rigen a las metáforas parece estar preparando el camino para la postura exagerada que asumirá luego.

Quiere para sí mismo ya un lugar entre los clásicos, pero no asume esto directamente. Tampoco lo hace el Borges de Otras inquisiciones; pues debe agregarse que este segundo Borges relativiza, de una manera que no conoce el Borges joven, el status de libro o autor clásico. En el ensayo dedicado a este tema se establece que se trata de un status al que se accede por causa de las formas de lectura: "Clásico no es un libro (lo repito) que necesariamente posee tales o cuales méritos; es un libro que las generaciones de los hombres, urgidas por diversas razones, leen con previo fervor y con una misteriosa lealtad" (1983: 246). La pertenencia al selectísimo grupo no está, pues, asegurada, por mucho que se la busque.

\section{7. $\quad$ Mapa de este jardín}

Hemos realizado una excursión por dos ejercicios de crítica literaria que responden a momentos diversos de la producción borgesiana. A propósito, hemos procedido de manera global. Buscábamos darnos una plataforma general desde la cual abordar los problemas posteriores, que por el momento entrevemos así: uno, habrá que proceder al examen detallado de cuáles son los espacios imaginativos que el Borges de Otras inquisiciones propone como recurrentes, y habrá -sobre todo-que examinarlos en el contexto del resto de la obra borgesiana contemporánea, para reforzar lo que aquí se ha dicho con respecto a la estrategia proyectiva de Borges sobre los espacios imaginativos que juzga fundamentales en el pensamiento y la historia humanos. Dos, habrá que examinar en la producción contemporánea a las Inquisiciones, el rumbo que tomó el Borges interesado en el criollismo; en particular, en El tamaño de mi esperanza, libro más de crítica literaria que El idioma de los argentinos. Quedan, pues, dos artículos por delante. 
Por el momento, una reflexión sobre los títulos nos parece válida. La "inquisición” a la que alude el texto de 1925 no es otra que la del crítico que asume el papel de juez, y que valora, califica, enaltece. Prefiere, eso sí, callar que valorar negativamente. Las inquisiciones posteriores son otras, porque son distintas: "otras" no apunta a la continuación, sino a la corrección. Ahora se habla desde el mismo espacio del discurso del juez, pero se ha corregido el creer que ese juez tiene los instrumentos de la valoración absoluta; se asume que la valoración procede de la lectura, no del texto sin más. También se sabe lo que es fundamental, se conocen los espacios de la imaginación que son "todo para todos", lo que ignoraba el joven Borges: el segundo juez ha ganado en sabiduría, pero ha perdido en autoridad.

\section{Bibliografía}

Alazraki, Jaime (ed.). 1976. Jorge Luis Borges. Madrid: Taurus.

1974. La prosa narrativa de Jorge Luis Borges. Madrid: Gredos.

Amoretti, María. 1992. Diccionario de términos asociados en teoría literaria. San José: Editorial de la Universidad de Costa Rica.

2002. Magón... la irresistible seducción del discurso. San José: Perro Azul.

Barone, Orlando (comp.). 1976. Diálogos entre Borges y Sábato. Buenos Aires: Emecé.

Barrenechea, Ana María. 1957. La expresión de la irrealidad en la obra de Jorge Luis Borges. México: Colegio de México.

Barthes, Roland. 1984. Crítica y Verdad. México: Siglo XXI.

Bastos, María Luisa. s.f. Borges antes la crítica argentina 1923-1960. Buenos Aires: Ediciones Hispanoamérica.

Benavides, Manuel. 1987. "Borges y la filosofía”. Cuadernos hispanoamericanos. Número 444: 118-126.

Block de Behar, Lisa. 1999. Borges. La pasión de una cita sin fin. México: Siglo XXI.

1984. Una retórica del silencio. México: Siglo XXI.

Bloom, Harold. 1995. El canon occidental. Barcelona: Anagrama.

Borello, Rodolfo. 1992. "Borges lector de las letras argentinas". Cuadernos hispanoamericanos. Número 505/507: 195-210.

Borges, Jorge Luis y Adolfo Bioy Casares. 1955. Poesía gauchesca. México: FCE. 
Borges, Jorge Luis. 1994a. El idioma de los argentinos. México: Seix Barral.

1994b. El tamaño de mi esperanza. México, Seix Barral.

1991. Ficciones. Buenos Aires: Alianza.

1989. El Aleph. Buenos Aires: Alianza.

1983. Otras Inquisiciones. Buenos Aires: Emecé.

1993. Inquisiciones. México: Seix Barral.

1980. Siete noches. Buenos Aires: Emecé.

1990. Obra poética 1923-1983. Madrid: Alianza.

1970. Conversations with Jorge Luis Borges. New York: Avon.

Cabo Borda, Juan Gustavo. 1980. "Borges académico". Revista Hispanoamericana de Literatura. 17 (50).

Carrizo, Antonio. 1983. Borges el memorioso. Conversaciones de Jorge Luis Borges con Antonio Carrizo. México: Fondo de Cultura Económica.

Eco, Umberto. 1981. Lector in fabula. Barcelona: Lumen.

Fokkema, D.W. 1996. "Comparative Literature and the Problem of Canon Formation". Ed. Milan V. Dimic and Steven Tötösy de Zepetnek. Canadian Review of Comparative Literature. 23 (1): 51-66.

Frow, John. 1995. Cultural Studies and Cultural Value. Oxford: Oxford University Press.

Heltf, Nicolás. 1997. Jorge Luis Borges. Bibliografía completa. Buenos Aires: FCE.

Herrera, Bernal. 1987. "Borges y el conocimiento". Revista de Filología, Lingüística y Literatura. XIII (1): 71-87.

1997. Arlt, Borges y Cía. Narrativa rioplatense de vanguardia. San José: Editorial de la Universidad de Costa Rica.

Martínez Echeverri, Leonor y Hugo. 1997. Diccionario de filosofía. Colombia: Panamericana.

Martínez Fernández, José Enrique. 2001. La intertextualidad literaria. Madrid: Cátedra. 
Molins, Felipe. 1990. Jorge Luis Borges: el hombre espejo. Video Cine, People and Arts.

Montanaro, Óscar. 1989. "Las hojas del ciprés: clausura del proyecto literario de Jorge Luis Borges”. Revista de Filología, Lingüística y Literatura. XV (2): 7-12.

Nuño, Juan. 1986. La filosofía de Borges. México: FCE.

Olea Franco, Rafael. 1993. El otro Borges. El primer Borges. México: FCE, COLMEX.

Peicovich, Esteban. 1999. Borges el palabrista. Madrid: Ediciones libertinas.

Picado, Manuel. 1983. Literatura/Ideología/Crítica. San José: Editorial Costa Rica.

Pozuelo, J.M. y R.M. Aradra. 2000. Teoría del canon y literatura española. Madrid: Cátedra.

Rodríguez Monegal, Emir. 1964. "Borges como crítico literario”. En La palabra y el hombre (Revista de la Universidad Veracruzana). 31 (3): 411-417.

Ruffinelli, Jorge. "Borges y el ultraísmo: un caso de estética y política". Revista México. Año 2.3 (9): 155-174.

Salas, Horacio. 1994. Borges. Una biografía. Buenos Aires: Planeta.

Sorrentino, Fernando. 1973. Siete conversaciones con Jorge Luis Borges. Buenos Aires: Casa Pardo.

Todorov, Tzvetan. 1994. Crítica de la crítica. Barcelona: Paidós.

Van der Walde, Ecna. 1985. "Hacia una definición de la teoría literaria de Jorge Luis Borges". Revista de la Universidad Nacional. 1 (3): 32-35.

Vásquez, María Esther. 1977. Borges: imágenes, memorias, diálogos. Venezuela: Monte Ávila.

Vega, María José y Neus Carbonell. 1998. Literatura comparada: principios y métodos. Madrid: Gredos.

Wellek, René. 1972-1996. Historia de la crítica moderna 1750-1950. (7 vols.) Madrid: Gredos.

Zagal Arreguín, Héctor (comp.). 1999. Ocho ensayos sobre Borges. México: Publicaciones Cruz. 